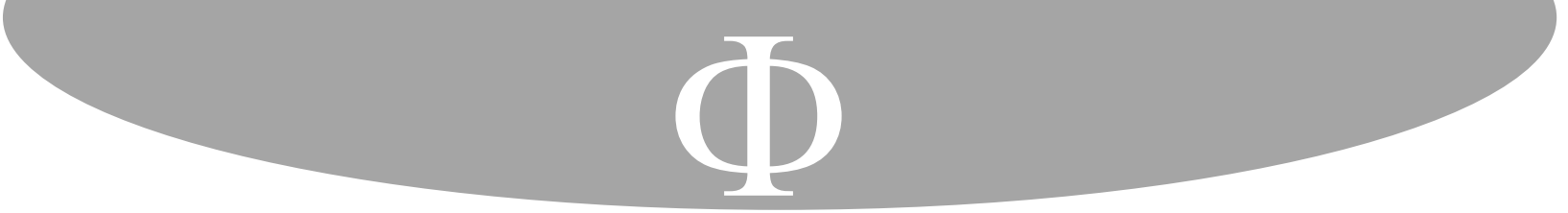

\title{
Espiritualidade Martirial: uma experiência de fé latino-americana*
}

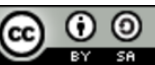

Para citar este artículo: Carvalho da Silva, Daniel. «Espiritualidade Martirial: uma experiência de fé latino-americana». Franciscanum 177, Vol. 64 (2022): 1-26.

\author{
Daniel Carvalho da Silva** \\ Pontifícia Universidade Católica de Goiás \\ Goiânia-GO, Brasil
}

\section{Resumo}

\begin{abstract}
O presente artigo traz à baila uma reflexão teórico-narrativa acerca daquela que tem sido chamada «Espiritualidade Martirial». A conceituação sobre espiritualidade e martírio deu-se por meio de pesquisa exploratório-bibliográfica. A discussão central foi tecida em diálogo, sobretudo, com os estudos teológicos de Casaldáliga, Sobrino e Gutierrez. As conclusões apontam no sentido de que a Espiritualidade Martirial não está relacionada ao desejo de ser mártir. Tampouco o martírio relaciona-se à concepção de sacrifício cruento como redentor de pecado. A Espiritualidade Martirial diz respeito à fidelidade ao Evangelho do perseguido e mártir, Jesus de Nazaré. De igual modo, diz respeito à fidelidade à realidade histórica atual e concreta na qual o cristão deve anunciar boas notícias aos pobres e denunciar a injustiça estrutural. Por fim, diz respeito à memória da morte dos inocentes e à fileira dos seguidores de Jesus que foram martirizados.
\end{abstract}

\section{Palavras-chave}

Espiritualidade, Martírio, Espírito de Jesus, Perseguição, Memória.

\section{Martirial Spirituality: A Latin American Faith Experience}

\begin{abstract}
This article brings up a theoretical-narrative reflection on what has been called «Martyrial Spirituality». The conceptualization of spirituality and martyrdom took place through exploratory-bibliographic research. The central discussion was woven in dialogue, above all, with the theological studies of Casaldáliga, Sobrino and Gutierrez. The conclusions point in the sense that Martyrdom Spirituality is not related to the desire to be a martyr. Nor
\end{abstract}

\footnotetext{
* O presente artigo é resultado das discussões empenhadas pela disciplina «Espiritualidade, holismo e consciência planetária» do Programa de pós-graduação em Ciências da Religião da Pontifícia Universidade Católica de Goiás durante o segundo semestre de 2020. O autor é discente, bolsista da Coordenação de Aperfeiçoamento de Pessoal de Nível Superior (Capes).

** Licenciado em Filosofia (IFITEG) e em Letras-Libras (UFG). Mestrando em Ciências da Religião (PUC Goiás / CAPES). Atualmente também realiza pós-graduação - em nível de especialização - em Liturgia Cristã (FAJE/Rede Celebra). ORCID: https://orcid.org/0000-0002-8700-4113. Contacto: dancarvalho90@ gmail.com.
} 


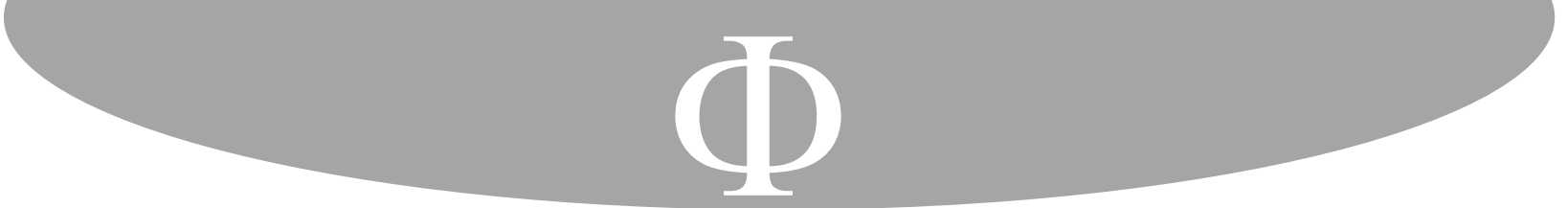

is martyrdom related to the conception of the bloody sacrifice as the redeemer of sin. Martyrdom Spirituality concerns fidelity to the Gospel of the persecuted and martyr, Jesus of Nazareth. Likewise, it concerns fidelity to the current and concrete historical reality in which the Christian must announce good news to the poor and denounce structural injustice. Finally, it concerns the memory of the death of the innocent and the line of followers of Jesus who were martyred.

\section{Keywords}

Spirituality, Martyrdom, Spirit of Jesus, Persecution, Memory.

\section{Espiritualidad Martirial: una experiencia de fe latinoamericana.}

\section{Resumen}

Este artículo plantea una reflexión teórico-narrativa sobre lo que se ha denominado «Espiritualidad martirial». La conceptualización de la espiritualidad y el martirio se realizó a través de una investigación exploratorio-bibliográfica. La discusión central se tejió en diálogo, sobre todo, con los estudios teológicos de Casaldáliga, Sobrino y Gutiérrez. Las conclusiones apuntan en el sentido de que la espiritualidad del martirio no está relacionada con el deseo de ser mártir. El martirio tampoco está relacionado con la concepción del sacrificio sangriento como redentor del pecado. La espiritualidad del martirio se refiere a la fidelidad al Evangelio del perseguido y mártir, Jesús de Nazaret. Asimismo, se trata de la fidelidad a la realidad histórica actual y concreta en la que el cristiano debe anunciar la buena nueva a los pobres y denunciar la injusticia estructural. Finalmente, se trata del recuerdo de la muerte de los inocentes y de la línea de seguidores de Jesús que fueron martirizados.

Palabras clave

Espiritualidad, Martirio, Espíritu de Jesús, Persecución, Memoria.

\section{Introdução}

No dia 11 de outubro de 1976 foi assassinado, pela polícia militar, em Ribeirão Bonito, um pequeno vilarejo que surgia no interior do Estado de Mato Grosso, dentro do território eclesial da Prelazia de São Félix do Araguaia, o missionário jesuíta João Bosco Penido Burnier. O fato se deu quando ele e o bispo Pedro Casaldáliga tentavam libertar duas camponesas da tortura cometida pelos policiais em razão de conflitos fundiários na região. Em memória daquele martírio construiu-se no vilarejo, atualmente sede do município de Ribeirão Cascalheira, o Santuário dos Mártires da Caminhada Latino-Americana ao qual acorrem pessoas das Comunidades Eclesiais de Base (CEBs) de todo o Brasil por ocasião das romarias celebradas lá. Para comemorar os vinte e cinco anos do martírio do padre João Bosco, nos dias 17 e 18 de junho de 2001, realizou-se uma grande romaria. Durante a preparação que a antecedeu, levou-se a termo a ideia de criar a Irmandade dos Mártires da Caminhada: uma fraternidade comprometida a manter vivas as memórias dos mortos na luta por justiça social e em defesa dos direitos humanos na América Latina. Composta por alguns familiares dos mártires, comunidades cristãs, grupos ligados às causas sociais e pessoas que 


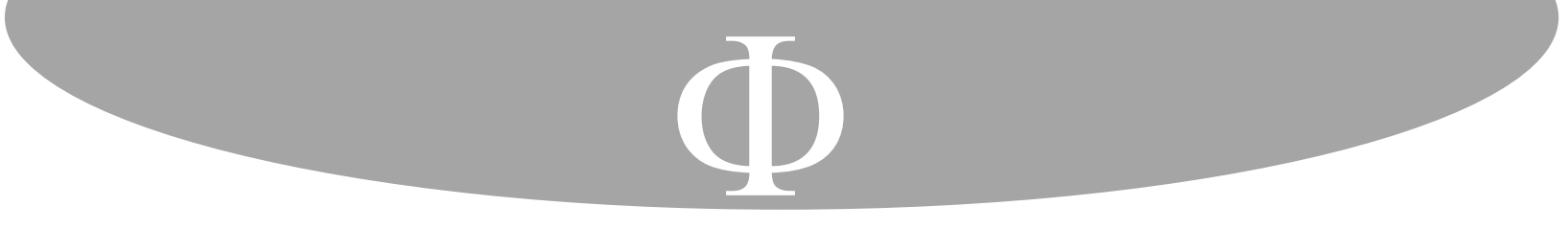

referência teológica tenha caducado. De fato, atualmente diminui o número de cristãos que se identificam com a Teologia da Libertação no Brasil. Contudo, a Irmandade dos Mártires da Caminhada tem crescido quantitativamente nos últimos anos. Além disso, acreditamos ainda que uma experiência de fé, por menor que seja o grupo que a professe, merece ser refletida pelos teólogos e cientistas da religião.

Para levar adiante tal empreita, retomamos uma definição de C. Boff que distingue o conceito de espiritualidade desde os prismas da antropologia e da teologia. Diz o autor:

Antropologicamente, [espiritualidade] trata-se do espírito humano: as atitudes de fundo com que se milita, as causas e motivações que sustentam o próprio compromisso. É o que empolga, entusiasma. É a paixão que sustenta e move a ação. Mas teologicamente e mais radicalmente, refere-se ao Espírito de Deus, às inspirações, luzes e energias que infunde no cristão comprometimento na política. É a paixão de Deus em nossa vida, o entusiasmo que infunde o Espírito de Deus em nossas ações ${ }^{8}$.

Essa pesquisa seguirá, obviamente, em primeiro nível de proximidade, o segundo aspecto teológico destacado por C. Boff. Por isso, parece coerente revisitar a teologia católica para aprofundar, também em caráter histórico, como foi e é compreendida a espiritualidade cristã no catolicismo. O primeiro passo, certamente, tange a relação nem sempre clara entre espírito e espiritualidade. Sobre tal, a indagação de Daniélou é imperiosa. Ei-la:

Quando falamos de 'espírito', quando dizemos que 'Deus é espírito', o que queremos dizer? Falamos grego ou hebraico? Se falamos grego dizemos que Deus é imaterial, etc. Se falamos hebraico dizemos que Deus é um vento forte, uma tempestade, uma força irresistível. Daqui provêm todas as ambiguidades quando se fala de espiritualidade. A espiritualidade consiste em se tornar imaterial ou em ser animado pelo Espírito Santo? ${ }^{9}$

Costa afirma que a tradição bíblica aponta para segunda opção e, nesse sentido, o espiritual está mesmo ligado à presença ativa de Deus. Apesar disso, o autor afirma:

No século XII, o termo spiritualitas (o qual, traduzido do grego pneumáticos é o precursor do nosso termo espiritualidade) começa a ser usado não só no seu sentido primitivo, como poder de Deus que anima a vida cristã, mas como «algo que diz respeito à alma enquanto em contraste com o corpo», com uma visão muito negativa da corporeidade $^{10}$.

O resultado foi que a espiritualidade passou a ser um empreendimento pessoal em busca da perfeição. Assim, a categoria «teologia mística», cunhada pelo Areopagita para designar o conhecimento revelado aos cristãos quando eles se deixavam transformar por

\footnotetext{
${ }^{8}$ Clodovis Maria Boff, «Espiritualidade do militante (com enfoque pneumatológico)», em Fé e política: fundamentos, ed. Pedro Ribeiro de Oliveira (Aparecida, SP: Idéias \& Letras, 2004), 191.

${ }^{9}$ Citado por: Alfredo Sampaio Costa, «Teologia e espiritualidade: em busca de uma colaboração recíproca», Perspectiva Teológica Vol. 38 (2006): 327, consultado em janeiro 02, 2021, http://faje.edu.br/periodicos/index.php/perspectiva/article/view/21/50.

${ }^{10}$ Alfredo Sampaio Costa, «Teologia e espiritualidade: em busca de uma colaboração recíproca»: 329.
} 


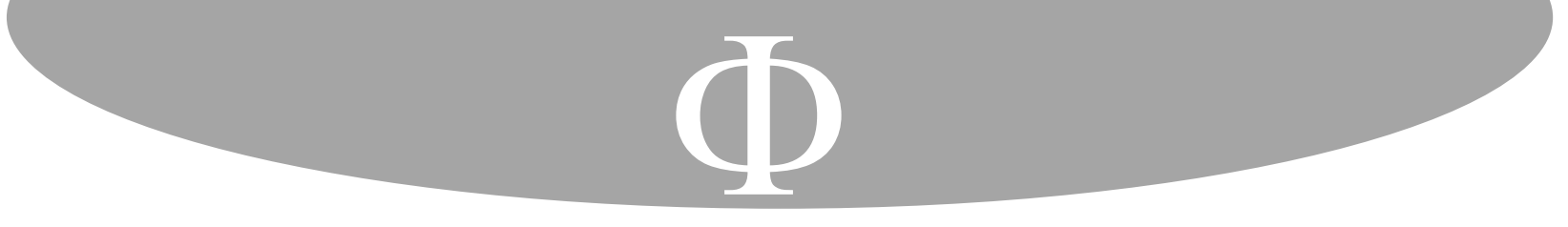

Deus, passou a ser empregado para traduzir certas técnicas de santificação da alma. A mística, nesse sentido, passou a ser compreendida não mais como a dimensão mais profunda da espiritualidade, mas como uma espécie de «recompensa da graça após a luta ascética, ou ainda, como um conjunto suspeito de experiências paranormais e de comportamentos estranhos» ${ }^{11}$. Tratava-se de uma distorção daquilo que era central nos primórdios do cristianismo: a introdução da vida humana no mistério de Cristo de modo a promover um crescente envolvimento comunitário e litúrgico que possibilitava uma abertura ao conhecimento revelado por Deus. Essa distorção, na compreensão de Costa, era o princípio da separação entre a teologia espiritual característica dos santos padres e uma nascente ciência da alma que resultaria, na contemporaneidade, como possibilidade de se falar em espiritualidades que independem da revelação de Deus e baseiam-se na progressão humana em direção a sua essência, seu autoconhecimento, sua felicidade.

De fato, hoje, fala-se sobre espiritualidades laicas, sem crenças, sem deuses ${ }^{12}$, sem igrejas $^{13}$, sem religiões ${ }^{14}$, baseadas na meditação ou em outras técnicas de integração humana $^{15}$. No âmbito do cristianismo, contudo, a espiritualidade continuou balizada entre a condução da vida pelo Espírito de Deus e as experiências místicas. No segundo caso, sempre ligada a experiências da alma como algo desvinculado do corpo. Não obstante, muitas outras ramificações identificadas como espiritualidade surgiram no contexto cristão. De modo geral, espiritualidade traduz a busca por uma existência alimentada ou preenchida de sentido pela relação com Deus. Daí provém os diversos adjetivos justapostos à palavra espiritualidade. As pessoas que alimentam sua fé na liturgia nomearão ao que experimentam por Espiritualidade Litúrgica ${ }^{16}$; os que buscam nutrir-se na Bíblia, Espiritualidade Bíblica ${ }^{17}$; os que perscrutam os desígnios divinos na luta por justiça social, Espiritualidade Militante ${ }^{18}$; os que vão pela via da oração, Espiritualidade Contemplativa; os que se integram a missões entre povos diferentes, Espiritualidade da Encarnação, e assim por diante. Até que se possa falar de espiritualidade matrimonial, laical, dos ministros ordenados, catequética, ativa, histórica, do trabalho, da pregação e outras ${ }^{19}$.

\footnotetext{
${ }^{11}$ Alfredo Sampaio Costa, «Teologia e espiritualidade: em busca de uma colaboração recíproca»: 329.

12 Marià Corbí, Para uma espiritualidade leiga: sem crenças, sem religiões, sem deuses (São Paulo: Paulus, 2010).

${ }^{13}$ Alonso S. Gonçalves, «Uma espiritualidade sem Igreja: a emancipação institucional e o surgimento de novas experiências religiosas», Protestantismo em Revista 32 (2013), consultada em janeiro, 02, 2021, http://periodicos.est.edu.br/index.php/nepp/article/view/1088/1068.

${ }^{14}$ Alberto Moreira, «Religiosidade laica: uma introdução ao pensamento de Marià Corbí», Horizonte - Revista de Estudos de Teologia e Ciências da Religião 19 (2011), consultada em janeiro 03, 2021, http://periodicos.pucminas.br/index.php/horizonte/article/view/P.2175- 5841.2010v8n19p21.

${ }^{15}$ Marià Corbí, Silencio desde la mente: prácticas de meditación (Barcelona: Bubok, 2011).

16 Burkhard Neunheuser, «Espiritualidade litúrgica», em Dicionário de Liturgia, ed. Domenico Sartore e Achille Triacca (São Paulo: Paulinas, 1992).

${ }^{17}$ Tereza Cavalcanti, Espiritualidade Bíblica (São Leopoldo: CEBI, 1996).

${ }^{18}$ Clodovis Maria Boff, «Espiritualidade do militante (com enfoque pneumatológico)», 191-214.

19 Victor Manuel Fernández, Teologia espiritual encarnada: profundidade espiritual em ação (São Paulo: Paulus, 2007).
} 


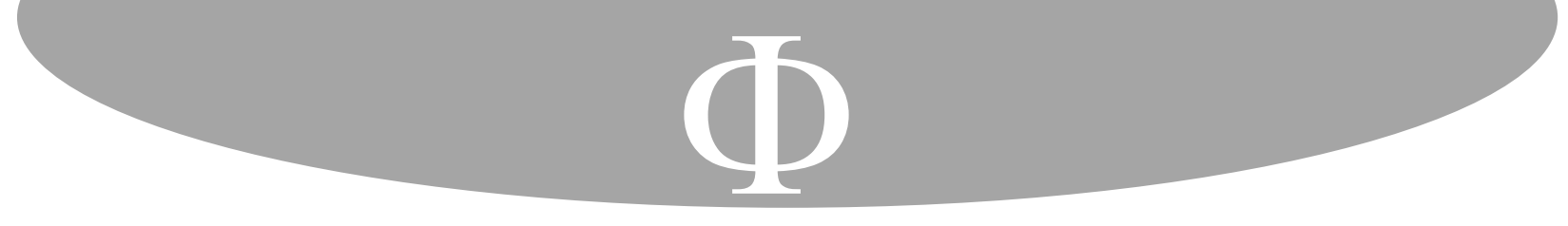

\title{
4. A lógica do sacrifício subjacente ao martírio
}

Ao martírio sempre subjaz uma força transformadora. É difícil ficar indiferente à morte de alguém indefeso que se entrega em nome de uma causa. Aliás, ainda que lhes faltem causas é comum no catolicismo popular brasileiro que os mortos de forma trágica ou violenta sejam, de certo modo, sacralizados pelo povo. São os casos, por exemplo, de Jandira «a prostituta milagreira» em Campinas, interior de São Paulo; de Maria Degolada, em Porto Alegre; ou ainda, das «treze almas benditas», em referência às vítimas carbonizadas no elevador do Edifício Joelma, em 1974, na cidade de São Paulo ${ }^{57}$. Desde o prisma cristão é também impossível desvincular aquele que doa totalmente a vida da figura do Servo de Javé em seu quarto canto:

\begin{abstract}
eram nossos sofrimentos que ele levava sobre si, nossas dores que ele carregava (...) foi trespassado por causa das nossas transgressões, esmagado por causa das nossas iniquidades. O castigo que havia de trazer-nos paz, caiu sobre ele, sim, por suas feridas fomos curados. (...) Foi maltratado, mas livremente humilhou-se e não abriu a boca. Porém ele se oferece a sua vida como sacrifício expiatório. (...) o justo, meu Servo, justificará a muitos e levará sobre si as suas transgressões (...) visto que entregou a si mesmo à morte e foi contado entre os criminosos, mas na verdade levou sobre si o pecado de muitos e pelos criminosos fez intercessão. (Is 53,4-12 - com supressões).
\end{abstract}

Ellacuría $^{58}$, ao escrever sobre a presença histórica de Cristo crucificado nos povos da América Latina - e especialmente de El Salvador, onde viveu até ser assassinado - sublinhou o duplo aspecto que o Servo desempenha. Por um lado, ele toma o pecado sobre si para ser destruído com ele, por outro, será luz e salvação para os povos. Essa profecia acerca do Servo, desde muito cedo, foi aplicada ao martírio de Jesus. O evangelista João $(1,29)$ narra que João Batista, ao indicar Jesus aos seus discípulos, utiliza o vocábulo aramaico talya, comumente traduzido por «cordeiro». No entanto, conforme Dautzenberg ${ }^{59}$, talya pode significar também «servo» ou «menino». Na sequência do mesmo texto (Jo 1,34), o batista afirma: «ele é o Eleito de Deus», numa clara alusão ao primeiro canto do Servo de Javé em Is 42,1+, para reafirmar que Jesus é o servidor sobre o qual Deus colocou seu Espírito. De igual modo, Lucas, ao registrar seu evangelho, retoma o quarto canto do Servo, citado diretamente acima, para dar a compreender o suplício do mestre galileu: «Ele foi contado entre os iníquos» (Lc 22,37) e ainda «Eram conduzidos também dois malfeitores para serem executados com ele» (Lc 23,32).

O judaísmo, por sua vez, esteve ligado ao sacrifício cruento, como prescrevia a lei de Moisés (cf. Es 3,2), especialmente depois do retorno do exílio na Babilônia e da reconstrução do Templo de Jerusalém. Dito de modo muito sucinto, o sacrifício de animais no Templo tinha a função de sanar o pecado do povo e reaproximá-lo de Deus (cf. Lv 16,1-30). Mas a

\footnotetext{
${ }^{57}$ José Reinaldo Felipe Martins Filho, Música e identidade no catolicismo popular: um estudo sobre a Folia de Reis e a Romaria ao Divino Pai Eterno em Goiás (São Paulo: Terceira Via, 2020), 146-147.

58 Ignácio Ellacuría, «El pueblo crucificado: ensayo de soteriología histórica», Revista Latinoamerica de Teología 18 (1989): 305-333.

${ }^{59}$ Gehard Dautzenberg, «Amnós-Cordero», em Diccionário exegético del Nuevo Testamento, ed., Horst Balz (Salamanca: Sigueme, 1996), 211.
} 


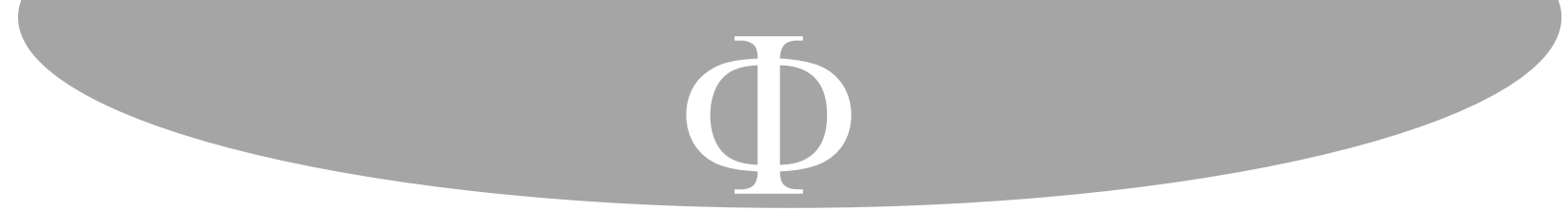

A palavra Sacrifício vem do latim sacrum-facere que significa fazer, tornar sagrado ${ }^{64}$. $\mathrm{O}$ ato de tornar sagrado depende do oferecimento, da entrega daquilo que se quer oferecer, doar, sacrificar a Deus. E o martírio foi sempre entendido exatamente como doação da vida. Aldazábal $^{65}$ afirma ainda que oferecimento «supõe sempre uma renúncia (imolação) de si ou das próprias posses». Nesse sentido, quando o padre João Bosco, na agonia da morte, oferecia seu sofrimento pelos indígenas, pelo povo... ${ }^{66}$ ele estava afirmando que aquela morte era resultado da entrega de sua vida, da doação cotidiana que fazia desde tempos anteriores e que agora oferecia, entregava, doava inteira e plenamente, uma vez que se desprendia de si mesmo completamente.

Uma analogia que pode ajudar a compreender a acepção acerca do sacrifício que destacamos aqui pode ser feita em referência à primeira frase da Introdução Geral do Ritual de Benção da Igreja Católica. A saber: «Fonte e origem de toda benção é Deus, bendito acima de tudo» ${ }^{67}$. Para compreendê-la, busquemos a estrutura dos textos de benção. Será sempre um bendizer a Deus pelo elemento ou pessoa que se quer abençoar ${ }^{68}$. Ademais, o conteúdo central das bênçãos maiores - como a da água na vigília pascal ou aquelas das preces de ordenação - é a memória das ações de Deus realizadas na história da salvação. No caso da benção da água, o texto recorda e bendiz pela água da criação, pela do dilúvio, pela do mar vermelho e pela do peito aberto de Jesus na cruz para, somente depois disso, invocar «desça sobre toda esta água a força do Espírito Santo» ${ }^{69}$. O central não é a invocação da benção, mas a ação de graças a Deus pela água. Abençoar requer bendizer a Deus. Sacrificar requer oferecer a Deus. Aquilo sobre o qual se bendiz a Deus torna-se bento, abençoado. Aquilo que se oferece a Deus torna-se sacro, sacrificado.

Em latim há duas palavras para designar o ato de tornar uma coisa sagrada, a saber, consacrare (consagrar) e sacrificium (sacrifício). No geral, as coisas e pessoas - como os religiosos e os altares - são «consagradas» e não «sacrificadas» para o serviço de Deus ou o uso litúrgico. Não é o que ocorre com a Eucaristia. No diálogo introdutório à anáfora, aquele que preside convida: «Orai, irmãos, para que o nosso sacrifício seja aceito por Deus Pai todopoderoso ${ }^{70}$. O que é sacrificado esteve sempre mais relacionado ao alimento apresentado a Deus e, no contexto judaico, aos animais usados para a expiação. Todo modo, a relação que expusemos anteriormente não está excluída. Pensemos, por exemplo, em Inácio de Antioquia em sua carta aos romanos escrita a caminho de sua execução: «Deixai-me ser alimento das

\footnotetext{
${ }^{64}$ José Aldazábal, Vocabulário básico de liturgia (São Paulo: Paulinas, 2013), 333.

65 José Aldazábal, Vocabulário básico de liturgia, 334.

${ }^{66}$ Pedro Casaldáliga, Martírio do Pe. João Bosco Penido Burnier (São Paulo: Loyola, 2006), 17.

${ }^{67}$ Ritual de bênçãos. Em Presbiteral. Ed. Alberto Beckauser (Petrópolis: Vozes, 2008), 619.

68 Veja por exemplo a oração de apresentação das oferendas na missa: «Bendito sejais, Senhor, Deus do universo, pelo pão que recebemos de vossa bondade, fruto da terra e do trabalho humano, que agora vos apresentamos e para nós se vai tornar pão da vida» Missal Romano, Promulgado por Paulo VI (São Paulo: Vozes/Paulinas, 1992), 402.

${ }^{69}$ Missal Romano, Promulgado por Paulo VI, 286-287.

${ }^{70}$ Missal Romano, Promulgado por Paulo VI, 403.
} 


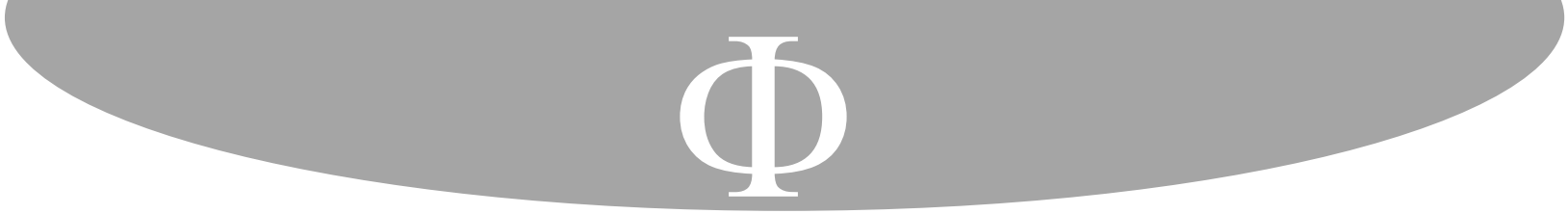

feras; por elas pode-se alcançar a Deus. Sou o trigo de Deus, serei triturado pelos dentes das feras para tornar-me o pão puro de Cristo ${ }^{71}$.

De outro modo, Dussel ${ }^{72}$ afirma:

Martírio, profecia e eucaristia são uma e a mesma coisa. Por isso a comunidade de base primitiva era um grupo de crentes que testemunhavam a sua fé, na comunidade de bens onde todos tinham o necessário, e por isso, «'rompiam o pão» fruto de seu trabalho, na justiça e na alegria (At 2,46 e 4,32). Na Eucaristia se oferece o «pão da vida», pão que é fruto do trabalho na justiça oferecido pela comunidade. No martírio o corpo do mártir é o pão do sacrifício («Este é o meu corpo»), pão da vida que se imola pela denúncia de que o pão não é comido pelo pobre («... e me destes de comer!») [em referência a Eclo 34,25: «escasso alimento é o sustento do pobre»], mas desapropriado, e por isso causa de sua pobreza, de seu sofrimento, de sua morte.

Nesse sentido (e somente nesse) o martírio pode ser identificado ao sacrifício, mas em clara contraposição à teologia que apregoava a necessidade do holocausto como via de perdão dos pecados. O sangue debaixo do altar grita a Deus por justiça (Ap 6,9-10), mas não justifica o pecado. O martírio é, então, o último ato de uma vida inteira doada em nome da justiça e da fé no Deus de Jesus de Nazaré. Tão doada que chega à morte.

Nesse âmbito, Gutierrez ${ }^{73}$ é categórico: 1) a admiração e o respeito pelo martírio não fazem esquecer a crueldade que o envolve e a repulsa às condições que permitem tal feita; 2 ) o martírio é algo que encontramos, não que buscamos; 3) queremos nossas testemunhas vivas para que continuem a ajudar o povo; 4) não desejamos e nem prestamos culto à morte; 5) o martírio será vivido, caso um dia ele seja imposto a nós, com a simplicidade de quem cumpre mais uma tarefa ${ }^{74}$; 6) a esperança da ressurreição não significa subterfúgio para a história concreta.

De fato, testemunhar a páscoa é anunciar que a vida vence a morte, mas, sobretudo, é dizer que não aceitamos que morra um pobre condenado à cruz. No fundo, isso implica aquilo que Barros afirma sobre a própria paixão de Jesus:

A espiritualidade da caminhada e, a partir dela, as teologias da libertação (teologias cristãs negras, indígenas, feministas e outras) têm nos ensinado a descontruir a teologia

\footnotetext{
${ }^{71}$ Inácio de Antioquia, «Carta aos Romanos», em Cartas de Santo Inácio de Antioquia (Petropólis: Vozes, 1970), 66.

${ }^{72}$ Enrique Dussel, «Palavras preliminares», em O martírio na América Latina. Ed. Ferrari (São Paulo: Loyola, 1984), 7-10.

${ }^{73}$ Gustavo Gutierrez, Gustavo Gutierrez, Beber em seu próprio poço: Itinerário Espiritual de um Povo, 130132.

${ }^{74}$ Gutierrez faz referência ao mártir jesuíta Luis Espinal, para afirmar que o povo não tem vocação de mártir. Confira: Luis Espinal, Oraciones a quemarropa (Barcelona: Rondas, 2020), consultado em janeiro 20, 2021, https://www.cristianismeijusticia.net/sites/default/files/pdf/eies92.pdf.
} 


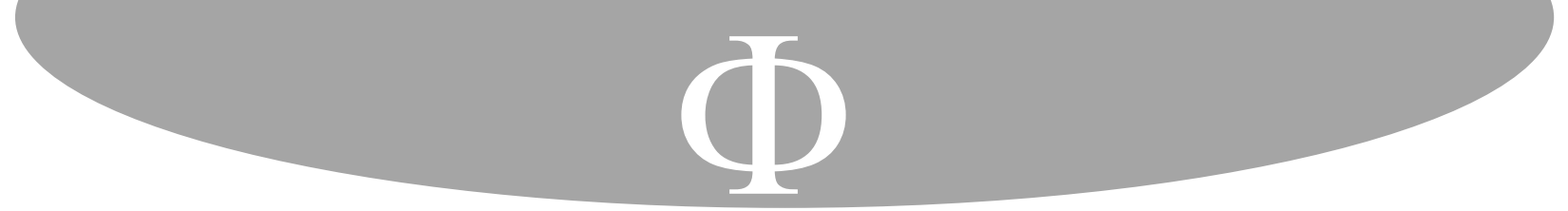

sacrificial e a compreender a paixão e ressurreição de Jesus nessa dimensão martirial, como testemunho do projeto divino no mundo e proposta de nova vida no Espírito ${ }^{75}$.

Desse modo, a constante acusação de que uma espiritualidade que tenha o martírio como ponto de referência reforça a teologia do sacrifício cruento - mesmo aqueles promovidos pelo deus-mercado - cai por terra. O Que há é luta para que o pobre viva - já que, como afirmara Romero ${ }^{76}$, esta é a glória de Deus. O que há é a assunção solidária das cruzes das vítimas, a fim de descer delas os povos crucificados ${ }^{77}$. O que há é fidelidade ao Espírito de Jesus $^{78}$. Parafraseando L. Boff, citado por Sobrino, não pode haver uma teologia do martírio, mas, sim, deve haver uma teologia que se faz a partir do martírio ${ }^{79}$. O mesmo se pode afirmar sobre a espiritualidade. Em seu aspecto libertador, a espiritualidade martirial é aquela feita, assumida e vivida sob o signo do martírio, mas não em vista dele.

\section{A síntese teórica de Sobrino}

Interessante e recordado por Bombonatto ${ }^{80}$ é o fato de que foi Romero quem pediu a Sobrino que se aprofundasse nos estudos teológicos a partir do martírio. A velha Europa pensava a dimensão martirial como um dado do cristianismo primitivo, mas não com uma realidade contemporânea ${ }^{81}$. Em face da perseguição à ala da Igreja de El Salvador que denunciava a repressão e o extermínio da população por parte do governo militar, Sobrino desenvolveu em sua teologia questões como: «O que é um mártir?» «O que fazer com nossos mártires?» e «O que exatamente confere sentido ao martírio?» ${ }^{82}$. Nessa seção debruçamonos sobre duas sínteses apresentadas pelo próprio autor que tendem a responder tais indagações. Uma foi publicada, em 2008, numa coletânea de textos sobre Casaldáliga. Outra, de 2014, cumpre o papel de prefácio no livro de Aquino-Júnior Viver segundo o espírito de Jesus Cristo.

\footnotetext{
75 Marcelo Barros, «Pedro Casaldáliga: o mártir que não conseguiram matar», Vida pastoral 337 (2021): 31 37, consultada em janeiro 14, 2021, https://www.vidapastoral.com.br/edicao/pedro-casaldaliga-o-martir-quenao-conseguiram-matar/

${ }^{76}$ Oscar Romero, La dimensión política de la fe desde la opción por los pobres. Una experiencia eclesial en El Salvador, Centroamérica [Discurso em Lovaina] (1980), 8. Consultado em janeiro 01, 2021. http://servicioskoinonia.org/relat/135.htm

77 Jon Sobrino, O princípio misericórdia: descer da cruz os povos crucificados (Petrópolis: Vozes, 1994).

78 Jon Sobrino, Jesus, o libertador: a história de Jesus de Nazaré (Petrópolis: Vozes, 1996).

79 Jon Sobrino, «Prefácio», em Viver segundo o espírito de Jesus Cristo: espiritualidade como seguimento, 8.

${ }^{80}$ Ivanise Bombonatto, Seguimento de Jesus na cristologia de Jon Sobrino. Dissertação (Mestrado em Teologia Sistemática). Pontifícia Universidade Católica de São Paulo, São Paulo (2012), 15.

${ }^{81}$ Salvas algumas exceções como quando o Papa João Paulo II afirmou, inclusive em âmbito ecumênico, que no final do segundo milênio a Igreja voltou a ser Igreja de mártires, em sua Carta Apostólica Tertio Millennio Adveniente, de 10/11/94. Ou como quando o Papa Francisco afirmou no Angelus, de 23/06/13, que hoje há mais mártires que nos primeiros séculos. Ou quando disse que todos os cristãos somos convidados ao «martírio branco», a doação da vida sem derramamento de sangue, na audiência geral de 25/09/19. Mas, de modo geral, não existem grandes estudos teológicos sobre o martírio atual.

82 Jon Sobrino, «A causa dos mártires», em Pedro Casaldáliga: as causas que imprimem sentido à sua vidaretrato de uma personalidade, 129-150.
} 


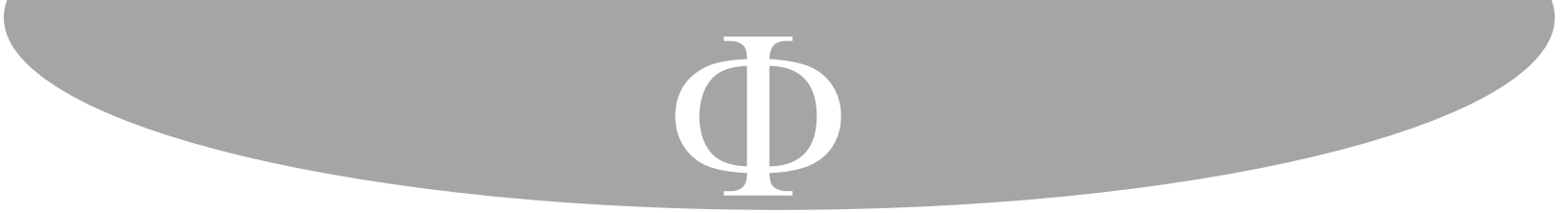

\section{Considerações finais}

Cipriano, ao instituir o jovem Aurélio como leitor da comunidade de Cartago, exortava a todos dizendo que é da leitura do Evangelho que os mártires são feitos ${ }^{91}$. De fato, como expusemos anteriormente, é o Evangelho vivido e anunciado por Jesus de Nazaré que dá sentido ao martírio. Ele provoca o comprometimento do cristão com a realidade. Ele aponta a necessidade de denunciar a injustiça e anunciar boas notícias aos pobres. Ele não promete vida fácil, mas perseguições e sofrimentos, inclusive na carne. Ele assegura a permanência de Jesus no cotidiano (cf. Mt 28,20) e o banquete na mesa do reino do Pai aos que forem fiéis até o fim (cf. Lc 22,28-30 e Mt 10,22). Mas, sobretudo, ele deixa o exemplo de Jesus (Jo 13,14), seu mandamento explícito «amar e dar a vida» (Jo 15,12-13) e simbólico «fazei isto em minha memória» (Lc 22,19), para que nós, seguidores, o imitemos.

A espiritualidade martirial, nesse sentido, diz respeito ao seguimento fiel a Jesus de Nazaré, que enfrentou os poderes de seu tempo até ser morto. Diz respeito também à fidelidade à realidade histórica atual e concreta na qual o anúncio do Evangelho deve se dar. Trata-se de viver a fé em um Deus ${ }^{92}$ que não promete e nem garante sucesso, como o definiu Bonhoeffer, em meio à tragédia que foi a Segunda Guerra Mundial: «Deus cravado na cruz, permite que o lancem do mundo. Deus é impotente e débil no mundo, e só assim Deus está conosco e nos ajuda» ${ }^{93}$. No mesmo sentido, a mensagem final do $9^{\circ}$ encontro Intereclesial das Comunidades Eclesiais de Base (CEBs), em São Luís do Maranhão, em 2008, afirmou: «vida vivida como Jesus é vitoriosa, mesmo se crucificada» ${ }^{94}$. Trata-se daquilo que o padre Júlio Lancelotti afirmou numa live em julho de 2020, acerca de seu trabalho pastoral com a população de rua, em São Paulo - SP, em meio à pandemia da Covid-19: «A minha perspectiva é o fracasso. Se eu tiver perspectiva de vencer é porque eu aderi a esse sistema» 95.

Como o apóstolo Paulo afirmou, a cruz de Cristo - instrumento e símbolo do fracasso - é motivo de orgulho para nós (cf. Gl 6,14). E, com ela, as tantas cruzes nas quais foram crucificados tantos dos seguidores de Jesus, também são motivo de orgulho, uma vez que a força de seus testemunhos desencadeia vida, provoca ressurreição. Mas não sem dor. Nesse sentido Casaldáliga escreveu:

Cantamos o sangue dos nossos melhores, a prova maior. Cobramos as flores de suas feridas, vivemos a vida que a morte ceifou. (...) No altar e nos braços erguemos, remidos,

\footnotetext{
${ }^{91}$ Cipriano de Cartago, Cartas (Madrid: Gredos, 1998) 172. Tradução nossa.

${ }^{92}$ Na perspectiva de: Jürgen Moltmann, O Deus crucificado: a cruz de Cristo como base e crítica da teologia cristã.

${ }^{93}$ Dietrich Bonhoeffer, Resistencia y sumision: cartas y apuntes desde el cautiverio (Barcelona: Ariel, 1969), 110. Tradução nossa.

${ }^{94}$ Carta do Intereclesial das CEB's, 2008, citada por: Francisco de Aquino Júnior, Viver segundo o espírito de Jesus Cristo: espiritualidade como seguimento, 43.

$\begin{array}{ccccc}95 & \text { Consultada } & \text { em } & \text { janeiro } & 20,\end{array}$

https://www.facebook.com/eduardomoreirabrasil/videos/605572867059786.
} 


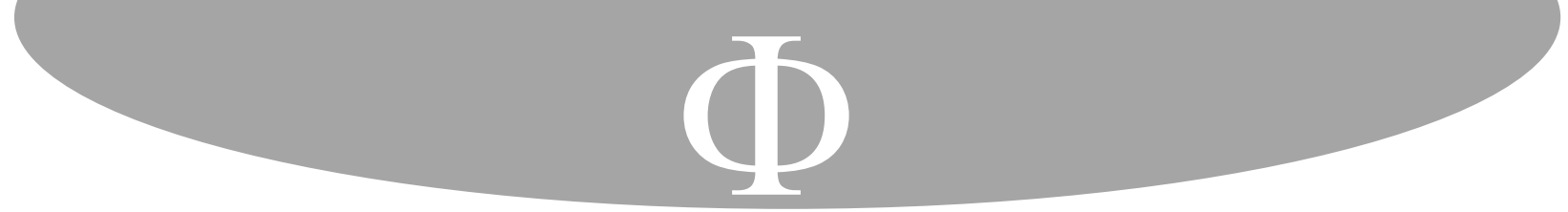

\section{Bibliografia}

Aldazábal, José. Vocabulário básico de liturgia. São Paulo: Paulinas, 2013.

Aquino-Junior, Francisco. Viver segundo o espírito de Jesus Cristo: espiritualidade como seguimento. São Paulo: Paulinas, 2014.

Barros, Marcelo. «Pedro Casaldáliga: o mártir que não conseguiram matar». Vida pastoral 337, (2021): 31-37. Consultado em Janeiro 14, 2021. https://www.vidapastoral.com.br/edicao/pedro-casaldaliga-o-martir-que-naoconseguiram-matar/.

Barros, Marcelo. «Pedro, místico». Em Pedro Casaldáliga: as causas que imprimem sentido à sua vida - retrato de uma personalidade. Editado por Benjamin Forcano, 347-358. São Paulo: Ave Maria, 2008.

Bernardo, T. «Memória como resistência: o migrante». Travessia Vol. 32 (1998): 40-47.

Bíblia do Peregrino. Comentários de Luís Alonso Schokel. São Paulo: Paulus, 2002.

Bingemer, Maria Clara. «Teologia e espiritualidade. Uma leitura teológico-espiritual a partir da realidade do movimento ecológico e feminista». Cadernos de Teologia Pública 2 (2004): 1-30. Consultado em Janeiro 04, 2021. http://www.ihu.unisinos.br/images/stories/cadernos/teopublica/002cadernosteologia publica.pdf.

Boff, Clodovis Maria. «Espiritualidade do militante (com enfoque pneumatológico)». Em Fé e política: fundamentos. Editado por Pedro Ribeiro de Oliveira, 191-214. Aparecida, SP: Idéias \& Letras, 2004

Bombonatto, Ivanise. Seguimento de Jesus na cristologia de Jon Sobrino. Dissertação (Mestrado em Teologia Sistemática). Pontifícia Universidade Católica de São Paulo, São Paulo, (2012).

Bonhoeffer, Dietrich. Resistencia y sumision: cartas y apuntes desde el cautiverio. Barcelona: Ariel, 1969.

Butler, Rex. The New Prophecy and «New Visions»: Evidence of Montanism in the «Passion of Perpetua and Felicitas». Washington: Catholic University of America Press, 2006.

Casaldáliga, Pedro. «Hino da caminhada dos Mártires». Em Caminhada dos Mártires. Editado por Cireneu Kuhn. Intérprete: Luiz Augusto Passos. São Paulo: Verbo Filmes, 1997. $1 \mathrm{CD}$, faixa 1.

Casaldáliga, Pedro. Martírio do Pe. João Bosco Penido Burnier. São Paulo: Loyola, 2006.

Casaldáliga, Pedro; Vigil, José Maria. Espiritualidade da libertação. São Paulo: Vozes, 1993.

Catecismo da Igreja Católica. São Paulo: Loyola, 1999.

Catré, Maria Nazarete Costa Catré; Ferreira, Joaquim Armando; Pessoa, Tereza; Catré, Acácio; Catré, Maria Costa. «Espiritualidade: contributos para uma clarificação dos conceitos». Análise Psicológica 1, v. 34, (2016): 31-46. Consultada em janeiro 10, 2021. $\quad$ http://www.scielo.mec.pt/scielo.php?script=sci_arttext\&pid=S087082312016000100003

Cavalcanti, Tereza. Espiritualidade Bíblica. São Leopoldo: CEBI, 1996.

Cipriano de Cartago. Cartas. Madrid: Gredos, 1998.

Corbí, Marià. Para uma espiritualidade leiga: sem crenças, sem religiões, sem deuses. São Paulo: Paulus, 2010.

Corbí, Marià. Silencio desde la mente: prácticas de meditación. Barcelona: Bubok, 2011. 


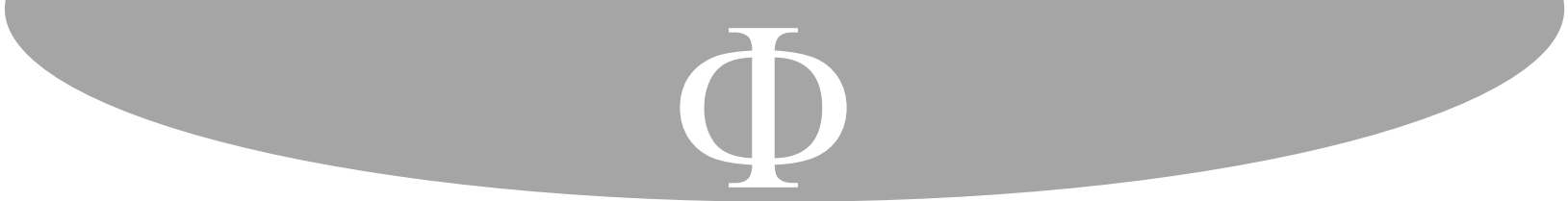

Costa, Alberto Sampaio. «Teologia e espiritualidade: em busca de uma colaboração recíproca». Perspectiva Teológica v. 38, (2006): 323-348. Consultado em janeiro 02, 2021. http://faje.edu.br/periodicos/index.php/perspectiva/article/view/21/50

Dussel, Enrique. «Palavras preliminares», Em $O$ martírio na América Latina. Editado por Ferrari, 7-10. São Paulo: Loyola, 1984.

Ellacuría, Ignácio. «El pueblo crucificado: ensayo de soteriología histórica». Revista Latinoamerica de Teología 18 (1989): 305-333.

Espinal, Luis. Oraciones a quemarropa. Barcelona: Rondas, 2020. Consultado em janeiro 20, 2021. https://www.cristianismeijusticia.net/sites/default/files/pdf/eies92.pdf

Eusébio de Cesaréia. História eclesiástica. Vol. 1. Itabaina/SE: Clube de autores, 2016.

Fernández, Victor Manuel. Teologia espiritual encarnada: profundidade espiritual em ação. São Paulo: Paulus, 2007.

Gehard Dautzenberg. «Amnós-Cordero». Em Diccionário exegético del Nuevo Testamento. Editado por Horst Balz, 210-217. Salamanca: Sigueme, 1996.

Gonçalves, Alonso. «Uma espiritualidade sem Igreja: a emancipação institucional e o surgimento de novas experiências religiosas». Protestantismo em Revista Vol. 32 (2013): 122-135. Consultada em janeiro 02, 2021. http://periodicos.est.edu.br/index.php/nepp/article/view/1088/1068

Gutierrez, Gustavo. Beber em seu próprio poço: Itinerário Espiritual de um Povo. São Paulo: Loyola, 2000.

Hartog, Paul. «The Christology of the martyrdom of Polycarp: Martyrdom as both imitation of Christ and election by Christ». Perichoresis 2, Vol. 12 (2014): 137-151. $\begin{array}{llll}\text { Consultada em } & \text { janeiro } & 06, & \end{array}$ https://content.sciendo.com/view/journals/perc/12/2/article-p137.xml?language=en.

Inácio de Antioquia. Carta aos Romanos. Petropólis: Vozes, 1970.

José Reinaldo Felipe Martins Filho, Clóvis Ecco, Marià Corbi. «Por uma espiritualidade profunda: uma entrevista a Marià Corbi», Caminhos 1, Vol. 15 (2017): 149-161. Consultada em março 30, 2021. http://dx.doi.org/10.18224/cam.v15i1.5973

José Reinaldo Felipe Martins Filho. Música e identidade no catolicismo popular: um estudo sobre a Folia de Reis e a Romaria ao Divino Pai Eterno em Goiás. São Paulo: Terceira Via, 2020.

Löwy, Michel. A guerra dos deuses: Religião e política na América Latina. Petrópolis: Vozes, 2000.

Manifestantes protestam pelo país contra a morte de Marielle Franco. Consultado em Janeiro 22, 2021. https://g1.globo.com/rj/rio-de-janeiro/noticia/manifestantes-protestampelo-pais-contra-a-morte-de-marielle-franco.ghtml.

Missal Romano. Promulgado por Paulo VI. São Paulo: Vozes/Paulinas, 1992.

Mo Sung, Jung. «Cristianismo de libertação: fracasso de uma utopia?». Estudos Teológicos 1, ano 48 (2008): 39-63. Consultada em janeiro 08, 2021. http://www3.est.edu.br/publicacoes/estudos_teologicos/vol4801_2008/et2008$1 \mathrm{c}$ jsung.pdf.

Moltmann, Jürgen. O Deus crucificado: a cruz de Cristo como base e crítica da teologia cristã. Santo André: Academia Cristã, 2011.

Moreira, Alberto. «Religiosidade laica: uma introdução ao pensamento de Marià Corbí». Horizonte - Revista de Estudos de Teologia e Ciências da Religião 19, Vol. 8, (2011): 
21-40. Consultada em janeiro 03, 2021: http://periodicos.pucminas.br/index.php/horizonte/article/view/P.21755841.2010v8n19p21.

Neunheuser, Burkhard. «Espiritualidade litúrgica». Em Dicionário de Liturgia. Editado por Domenico Sartore e A. Triacca, 370-388. São Paulo: Paulinas, 1992.

Oliveira, Davison Schaeffer. «O conceito de espiritualidade a partir de uma abordagem filosófica da subjetividade». Revista Brasileira de Filosofia da Religião 1, v. 3 (2016): 112-133. Consultada em janeiro 04, 2021. https://periodicos.unb.br/index.php/rbfr/article/view/14252/12571

Padres apostólicos. Martírio de São Policarpo, bispo de Esmirna. São Paulo: Paulus, 1997.

Paulo VI. Proclamazione di santa Teresa d'Avila dottore della chiesa: Omelia del santo padre. (1970). Consultado em janeiro 05, 2021. http://www.vatican.va/content/paulvi/it/homilies/1970/documents/hf_p-vi_hom_19700927.html

Ritual de bênçãos. Em Presbiteral. Editado por Alberto Beckauser, 617-772. Petrópolis: Vozes, 2008.

Romero, Oscar Arnufo. La dimensión política de la fe desde la opción por los pobres. Una experiencia eclesial en El Salvador, Centroamérica [Discurso em Lovaina]. (1980). Consultado em janeiro 20, 2021. http://servicioskoinonia.org/relat/135.htm

Schepelern, Willen. Der Montanismus und die phrygischen Kulte: Eine religionschichtlich untersuchung. Tubinga: Mohr Siebeck, 1929.

Sobrino, Jon. «A causa dos mártires». Em Pedro Casaldáliga: as causas que imprimem sentido à sua vida - retrato de uma personalidade. Editado por Benjamin Forcano, 129-150. São Paulo: Ave Maria, 2008.

Sobrino, Jon. «De una teología sólo de la liberación a una teología del martirio». Revista Latinoamericana de Teología 28, Vol. 10 (1993): 27-48. Consultado janeiro 04, 2021. http://www.redicces.org.sv/jspui/bitstream/10972/1201/1/RLT-1993-028-B.pdf

Sobrino, Jon. Espiritualidade da Libertação: estrutura e conteúdos. São Paulo: Loyola, 1992.

Sobrino, Jon. Jesus, o libertador: a história de Jesus de Nazaré. Petrópolis: Vozes, 1996.

Sobrino, Jon. O princípio misericórdia: descer da cruz os povos crucificados. Petrópolis: Vozes, 1994.

Sobrino, Jon. Os seis jesuítas mártires de El Salvador. São Paulo: Loyola, 1990.

Sobrino, Jon. Oscar Romero: profeta e mártir da libertação. São Paulo: Loyola, 1988.

Sobrino, Jon. «Prefácio». Em Viver segundo o espírito de Jesus Cristo: espiritualidade como seguimento. Editado por Francisco de Aquino Júnior, 7-10. São Paulo: Paulinas, 2014.

Sobrino, Jon. Terremoto, terrorismo, barbárie y utopia: El Salvador, Nueva York, Afganistán. San Salvador: UCA, 2005.

Tabbernee, Willian. «Early Montanism and voluntary martyrdom». Colloquium Vol. 17 (1985): 33-44. Consultado em janeiro 2021. https://www.academia.edu/27317663/Early_Montanism_and_Voluntary_Martyrdo $\underline{\mathrm{m}}$.

Taborda, Francisco. Sacramentos, práxis e festa: para uma teologia latino-americana dos sacramentos. São Paulo: Paulus, 2019. 


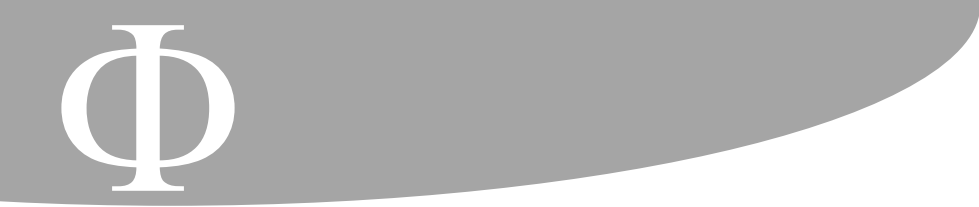

Tavares, Ana Helena. Um bispo contra todas as cercas: a vida e as causas de Pedro Casaldáliga. Rio de Janeiro: Gramma, 2019.

Tavares, Josimo Morais. Testamento espiritual de padre Josimo. (folha avulsa). (1986). Consultada em janeiro 25, 2021. http://cajui.uft.edu.br/proide-pn/acervo-damitra/242-acervo-da-mitra-diocesana-227.html

Teresa d'Ávila. «Versos nascidos do fogo do amor de Deus que tinha em Si». In Reachers, S. Em Breve antologia da poesia cristã universal. São Gonçalo - RJ: S. Reachers, 2012. Disponível em: https://www.passeidireto.com/arquivo/79027069/poesiacrista-universal-breve-antologia.

Turner, Victor. Dramas, campos e metáforas: ação simbólica na sociedade humana. Niterói: EdUFF, 2008.

Enviado: 11 de abril de 2021 Aceptado: 8 de junio de 2021 